\title{
Radiation Therapy of Tumours Involving the Skull Base
}

\author{
David G. Payne
}

\begin{abstract}
The author reviews the Princess Margaret Hospital (Ontario Cancer Institute) experience with radiation therapy in certain tumours involving the skull base including meningiomas, chordomas, craniopharyngiomas and other less common tumours. Radiation therapy offers an effective supplementary or alternative treatment for such lesions.
\end{abstract}

RÉSUMÉ: Thérapie par radiation des tumeurs envahissantes de la base du crâne L'auteur passe en revue l'expérience acquise au Princess Margaret Hospital (Ontario Cancer Institute) avec la thérapie par radiation de certaines tumeurs impliquant la base du crâne: méningiomes, chordomes, cranio-pharyngiomes et autres. La radiothérapie sert de traitement supplémentaire ou alternatif efficace de telles lésions.

Can. J. Neurol. Sci. 1985; 12:363-365

Management of tumours of the skull base poses unique challenges for both surgeon and radiation oncologist. The limits of any single therapeutic modality may be reached early in the course of the disease, and further treatment often involves a combined approach using more than one modality. Tumours arising in the skull base region are many and varied (Table 1). Many have a chronic natural history with or without treatment, and decision making about treatment frequently relies on factors of unknown prognostic influence. Factors entering into treatment decisions, such as the nature of the symptoms, prior history of the illness, the patient's wishes or the physician's previous experience with such cases, are likely to have a greater impact on the final outcome than the skills of the surgeon, radiation oncologist or chemotherapist. These factors, and indeed the endpoints by which the success of therapy is judged, such as quality of life, remain elusive and difficult to quantify. Such considerations, together with the rarity of most skull base tumours, render evaluation of therapeutic policies or techniques an uncertain task at best.

In this context, we must consider the role of radiation therapy in the management of skull base tumours. With a few exceptions (e.g. plasmacytoma, lymphoma, germinoma, metastatic carcinoma), radiation therapy should be regarded as supplemental to surgery, which remains the primary treatment, and which should be as radical as possible without producing undue morbidity. Radiation therapy may be given following surgery; it is a noninvasive yet local therapy, involving no tissue removal or systematic toxicity. The ability of the radiation oncologist to precisely specify the tissue concentration of his 'drug' within the target tissues remains a remote goal, and the efficacy of treatment is variable and difficult to predict. In addition radiation may damage structures in the neighbourhood of the tumour.

\section{Table 1: Tumours of the base of skull}

\begin{tabular}{|c|c|}
\hline Primary: & $\begin{array}{l}\text { craniopharyngioma } \\
\text { chordoma } \\
\text { plasmacytoma } \\
\text { osteogenic sarcoma } \\
\text { schwannoma } \\
\text { miscellaneous: } \\
\quad \text { lymphoma } \\
\quad \text { adenoid cystic ca } \\
\text { histiocytosis } \\
\text { hemangioma }\end{array}$ \\
\hline Secondary: & $\begin{array}{l}\text { extension: } \\
\text { meningioma } \\
\text { pituitary adenoma } \\
\text { glioma } \\
\text { (astro, oligo, ependymoma) } \\
\text { nasopharynx carcinoma } \\
\text { sinus carcinoma } \\
\text { germinoma } \\
\text { metastatic: } \\
\text { ca breast, lung, etc }\end{array}$ \\
\hline Others: & $\begin{array}{l}\text { granuloma } \\
\text { dermoid }\end{array}$ \\
\hline
\end{tabular}


In addition to conventional cobalt sources, radiation therapy may be administered by means of high energy equipment, such as a photon beam from a linear accelerator. Using computerized imaging techniques to determine beam and couch angles, together with custom made patient immobilization techniques, the radiation beams are made to overlap in a region which is specified to include the tumour. This results in relative sparing of non-involved tissues. Experimental programs in Boston, Berkeley, and Vancouver use cyclotrons to produce charged particles rather than photons. Such techniques may offer important clinical benefit through improved dose localization in the tumour and minimize dosage to nearby structures.

\section{Meningioma}

Meningiomas, because they are usually benign and most can be completely removed surgically, are rarely referred to the Ontario Cancer Institute Princess Margaret Hospital which is the radiation therapy centre for approximately four million people in Southern Ontario. Approximately 200 primary intracranial tumours are referred for radiation each year, yet only 102 patients with meningioma were referred in the 25 year period from 1958 to 1985 . Of 85 charts reviewed, there were 23 meningiomas involving the skull base. There were fifteen females and eight males. Symptoms most commonly began in the 4th or 5 th decade and the patients' ages ranged from 9 to 81 . The location of the tumours was not necessarily typical for meningioma, but reflected the selection process for a group of unresectable tumours (Table 2). No systematic method of selecting the tim-

Table 2: Site of meningiomas of skull base referred for radiation

$\begin{array}{lr}\text { Sphenoid/Cavernous Sinus } & 15 \\ \text { Ant. Fossa/Olfactory Groove } & 2 \\ \text { Post. Fossa/Clivus/Petrous } & 6\end{array}$

ing of radiation therapy in relation to the surgery was identified. Eighteen patients received radiation therapy. In five it was elected to withhold treatment and observe the patient. In spite of presumed residual disease, one patient, not radiated, is free of any evidence of progression 19 years later. Table 3 demonstrates that long survivals are possible with any of the various programs tried. However, the lack of proper control groups, and the small patient numbers make it impossible to determine the specific role of radiation or its optimal timing in relation to surgery. No adverse neurological effects of radiation were identified in this review.

Other studies have attempted to document benefit for radiation therapy (Table 4), but are subject to similar uncertainties of interpretation. The study by Wara' strongly suggests a reduction in recurrence rate in those patients treated with radiation therapy, but patient selection criteria are not stated. The results reported by Wara and by Carella ${ }^{2}$ are for all patients with meningioma, not just the subset involving the skull base. Effenterre $^{3}$ reported symptomatic improvement in eight patients with meningioma involving the cavernous sinus, but no objective or long term data are provided. Complete disappearance for at least four years of an extradural frontal meningioma $8 \mathrm{~cm}$ in diameter has been recorded. ${ }^{4}$ Fukui ${ }^{5,6}$ concluded that the angioblastic (hemangiopericytoma) type of meningioma may show a very good response, a conclusion that had previously
Table 3: Meningiomas of skull base: Status following radiation therapy

\begin{tabular}{|c|c|c|}
\hline $\begin{array}{l}\text { Surgery + early RT } \\
\text { (within first year) }\end{array}$ & 6 & $\begin{array}{l}3 \text { NEP } 2,2,20 \mathrm{yr} \text {. } \\
2 \text { DOD } 1,6 \mathrm{yr} \text {. } \\
1 \text { DOC } 1 \mathrm{yr} .\end{array}$ \\
\hline Surgery + late RT & 9 & $\begin{array}{l}6 \text { NEP } 2,11-25 \mathrm{yr} \\
2 \text { DOD } 1,6 \mathrm{yr} \text {. } \\
1 \text { DOC } 1 \mathrm{yr} .\end{array}$ \\
\hline RT only & 3 & $\begin{array}{l}1 \text { NEP } 9 \mathrm{yr} . \\
1 \text { DOD } 1 \mathrm{yr} \text {. } \\
1 \text { DOC } 1 \mathrm{yr} \text {. }\end{array}$ \\
\hline
\end{tabular}

(NEP: no evidence of progression, DOC: died of other cause, DOD: died of disease, RT: radiation therapy)

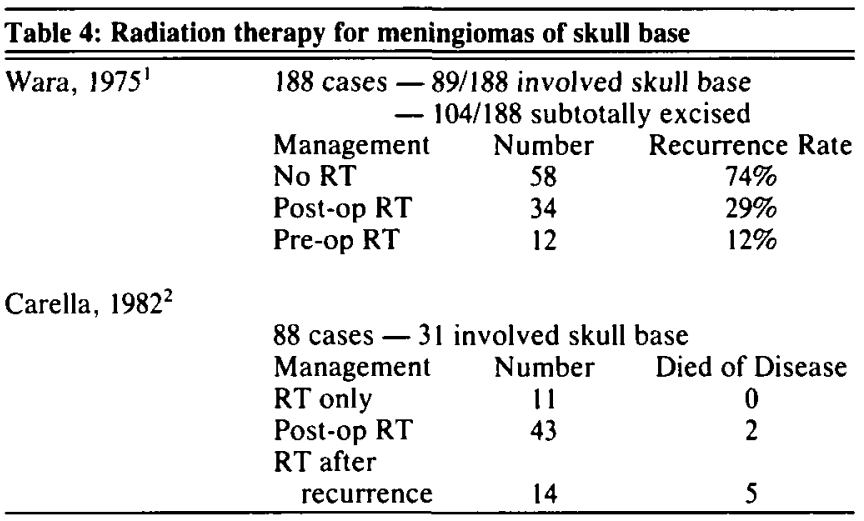

$\mathrm{RT}$ : radiation therapy

been suggested by King. ${ }^{7}$ A review by Yamashita ${ }^{8}$ in which 20 of 336 patients operated on for meningioma received radiation therapy because of recurrence, incomplete resection or malignant features, showed only minor benefit. Recent neuroophthalmological reports ${ }^{9,10}$ recommend radiation therapy for meningiomas involving the optic nerve. Petty et al ${ }^{11}$ in a review of twelve patients with incompletely resected meningiomas, eight of which involve the sphenoid region, conclude that radiation therapy delays recurrence and may contribute to prolonged survival.

The following case illustrates that surgery and radiation therapy can be judiciously combined to bring long term tumour control and relief of symptoms to the patient. A 55-year-old woman with left sided blindness and proptosis had a meningioma arising from the greater wing of the sphenoid bone. It was excised together with the involved greater wing, lateral orbital wall, and lateral two thirds of orbital roof, without entering Tenon's capsule. She remained well for 8 years, when left sided pain recurred, and exophthalmos and temporal lobe seizures developed. Conventional tomography showed dense sclerosis of the sphenoid bone and sinus, extending into the orbital roof and cribriform plate. She received cobalt- 60 radiation therapy to the anterior quadrant encompassing all involved bone and orbit, to a dose of 50 Gray in 24 fractions in five weeks. The patient's pain subsided, but marked exophthalmos $(25 \mathrm{~mm})$ persisted. One year after radiation an enucleation and removal of fibrous tissue was performed. No tumour was found in the surgical specimen. Her symptoms resolved and a CT examination ten years after radiation therapy showed minor soft tissue changes of uncertain significance along the medial aspect of the sphe- 
noid wing, but no evidence of mass effect or active neoplasm.

It is not possible to draw definite conclusions regarding the role of radiation therapy for meningiomas. At present, we reserve radiation for cases of known residual unresectable tumour, benign or malignant, which clearly demonstrate progression. Tumours not yet progressing, but which are residual in relatively inaccessible basal locations such as the region of the cavernous sinus or brain stem may also be considered for radiation treatment because of the serious consequences of tumour progression in those sites. Incompletely removed tumours manifesting malignant histologic features, even though their natural history may be fairly long, should probably also be treated.

\section{Other tumours involving the base of skull}

Since chordomas are incompletely resectable tumours, they are often radiated..$^{12}$ It has been suggested by Cummings ${ }^{13}$ that chordomas may be most effectively treated by a regimen of multiple daily fractions. The Ontario Cancer Institute experience with ten clivus chordomas showed a median survival of seven years, and a ten year survival of $30 \%$. This chronic course is typical, and renders difficult evaluation of the short follow-up results of proton beam therapy reported in six patients from Boston. ${ }^{14}$

In the management of craniopharyngioma, radiation therapy appears to be useful in controlling cyst formation. In some patients, marked improvement in visual symptoms occurred. Fewer than $10 \%$ of 54 patients at the Ontario Cancer Institute showed active disease after radiation therapy.$^{15}$ When medical factors render surgery hazardous, or when craniopharyngioma cysts recur, radiation therapy offers a reasonable alternative approach.

Certain other tumours respond well to radiation, and may require no more than surgical biopsy, followed by radiation therapy for their control. Examples include plasmacytoma, ${ }^{16}$ eosinophilic granuloma, lymphoma, some hemangiomas, ${ }^{17}$ glomus tumour, ${ }^{18}$ and angiofibroma. ${ }^{19}$

Radiation therapy is also effective for palliation of metastatic carcinoma invading the base of the skull, lesions that are not surgically resectable. A review by Vikram ${ }^{20}$ concluded that symptomatic relief may be obtained in up to three quarters of such patients, with little morbidity.

\section{Conclusion}

Radiation therapy offers an effective supplementary, and at times alternative treatment for patients with certain tumours involving the base of the skull, including incompletely resected meningiomas, chordomas and craniopharyngiomas. Our lim- ited experience with these uncommon tumours makes it difficult to draw firm conclusions as to the optimal dose parameters and long term benefits of radiation.

\section{REFERENCES}

1. Wara WM, Sheline GE, Newman $H$ et al. Radiation therapy of meningioma. Am J Roentgenology 1975; 123:453-458.

2. Carella RJ, Ransohoff J, Newall J. Role of radiation therapy in the management of meningioma. Neurosurg 1982; 10:332-339.

3. Effenterre R, Bataini JP, Cabanis EA et al. High energy radiotherapy in the treatment of meningiomas of the cavernous sinus. Acta Neurochirurgica Suppl 1979; 28:464-467.

4. Platt M, Khan FR, Nickson JJ et al. A case of extradural meningioma treated successfully with high energy electron. J Radiol Electrol 1974 ; 55:519-521.

5. Fukui M, Kitamura K, Nakagaki $\mathrm{H}$ et al. Irradiated meningiomas: A clinical evaluation. Acta Neurochirurgica 1980;54:33-43.

6. Fukui M, Kitamura K, Oghami S et al. Radiosensitivity of meningioma - analysis of five cases of highly vascular meningioma treated by preoperative irradiation. Acta Neurochirurgica 1977;36:47-60.

7. King DL, Chang CH, Pool JL. Radiotherapy in the management of meningiomas. Acta Radiologica Ther Phys Biol 1966; 5:26-33.

8. Yamashita J, Handa $\mathrm{H}$, Iwaki $\mathrm{K}$ et al. Recurrence of intracranial meningiomas, with special reference to radiotherapy. Surg Neurol $1980 ; 14: 33-37$.

9. Smith JL, McCrary JA, Ray BS. Managing menancing meningioma. J Clin Neuro-ophthalmol 1983; 3:169-179.

10. Smith JL, Vuksanovic MM, Yates BM et al. Radiation therapy for primary optic meningiomas. J Clin Neuro-ophthalmol 1983; 1:85-99.

11. Petty AM, Kun LE, Meyer GA. Radiation therapy for incompletely resected meningioma. J Neurosurg 1985; 62:502-507.

12. Cummings BJ, Esses $S$, Harwood AR. The treatment of chordomas. Cancer Treat Rev 1982; 9:299-311.

13. Cummings BJ, Hodson DI, Bush RS. Chordoma: the results of megavoltage radiation therapy. Int J Radiat Oncol Biol Phys $1983 ; 9: 633-642$.

14. Suit HD, Goitein M, Munzenrider J et al. Definitive radiation therapy for chordoma and chondrosarcoma of base of skull and cervical spine. J Neurosurg 1982; 56:377-385.

15. Kostashuk EC. Management of craniopharyngiomas. Presented at Canadian Association of Radiologists Meeting. Vancouver, B.C., June 1984.

16. Harwood AR, Knowling MA, Bergsagel DE. Radiotherapy of plasmacytoma of the head and neck. Clinical Radiol 1981; 1599-1605.

17. Miller D, De Wilde F. Haemangiomatous malformation of the orbitosphenoidal region: Cure by radiotherapy. Aust NZ J Surg $1976 ; 46: 67-69$.

18. Cummings BJ, Beale FA, Garrett PG et al. The treatment of glomus tumours in the temporal bone by megavoltage radiation. Cancer $1984 ; 53: 2635-2640$.

19. Cummings BJ, Blend R, Keane TJ et al. Primary radiation therapy for nasopharyngeal angiofibroma. Laryngoscope 1984; 94:15991605 .

20. Vikram B, Chu F. Radiation therapy for metastases to the base of the skull. Radiology 1979; 130:465-468. 